\title{
Análisis inmunohistoquimico y molecular de los genes de reparación en cáncer testicular
}

\author{
A. Velasco Palma*, E. Riquelme Sánchez**, M. Schulze Maroto**, L. Villarroel del Pino***, \\ F.S. Leach**** \\ *Departamento de Urología. **Departamento de Patología. ***Departamento de Salud Pública. Facultad de \\ Medicina. Pontificia Universidad Católica de Chile. Urology and Molecular and Human Genetics. \\ ****Scott Department of Urology, Baylor College of Medicine.
}

Actas Urol Esp 2005; 29 (2): 198-206

\section{RESUMEN}

ANALISIS INMUNOHISTOQUIMICO Y MOLECULAR DE LOS GENES DE REPARACION EN CANCER TESTICULAR

La corrección de los nucleótidos mal incorporados durante la replicación del ADN (sistema de reparación de genes) puede determinar un potencial biológico y clínico diferente en los tumores. En este trabajo investigamos la expresión inmunohistoquímica de los genes de reparación en cáncer de testículo en los distintos tipos histológicos, correlacionando el grado de expresión con la presencia de inestabilidad microsatélite y correlacionando ambas con la evolución clínica.

Pacientes y método: 118 casos de tumores testiculares fueron analizados molecularmente realizando inmunohistoquímica para hMLH1 y hMSH2. El análisis de inestabilidad microsatélite y LOH se realizó comparando ADN micro disecado de tejido tumoral y normal, el que fue amplificado mediante PCR con 10 marcadores preestablecidos.

Resultados: El grado de expresión de hMSH2 se correlaciona con el estadio del tumor $(\mathrm{p}<0,001)$ mientras que la sobreviva cáncer específica se correlaciona con el grado de expresión de hMLH1 ( $\mathrm{p}=0,036)$. Inestabilidad microsatélite se detectó en un 94\% y 92\% de los cánceres con baja expresión de hMLH1 y hMSH2 respectivamente. La recaída y muerte cáncer específica se correlacionan con el grado de inestabilidad genética $(\mathrm{p}=0,01, \mathrm{p}=0,04)$. Un $9 \%$ de los tumores presentan una bajo grado de expresión de los genes de reparación, inestabilidad microsatélite y un mal pronóstico.

Conclusiones: El grado de expresión de los genes de reparación así como la frecuencia de inestabilidad logran definir cánceres testiculares con diferentes propiedades moleculares y diferente pronóstico. Los genes de reparación usados en conjunto con la histología, los marcadores serológicos pueden ser determinantes en el manejo de los pacientes con tumores testiculares.

Palabras clave: hMSH2. hMLH1. Cáncer testicular. Microsatélite inestabilidad. Inmunohistoquímica.

\section{ABSTRACT}

IMMUNOHISTOCHEMICAL AND MOLECULAR ANALYIS OF MISMATCH REPAIR GENES IN GERM CELL TUMORS

Correction of misincorporated nucleotides during DNA replication (mismatch repair) distinguishes histologically similar cancers with distinct biological and clinical behavior. We investigated expression of two mismatch repair genes in testis cancer to determine the expression pattern in histologically distinct subtypes, correlate expression with genetic instability and correlate expression and genetic instability with clinical outcome.

Patients and methods: 118 cases of testis cancer were analyzed. Immunohistochemical analysis of paraffin embedded specimens utilized monoclonal antibody for hMLH1 and hMSH2 mismatch repair proteins. Genetic instability was determined by comparing genomic DNA from microdissected matched normal and tumor cells. PCR amplification of 10 genetic markers assessed loss of heterozygosity and/or microsatellite instability.

Results: hMSH2 staining was associated with pathologic stage $(\mathrm{p}<0.001)$ while hMLH1 staining was associated with cancer specific survival ( $\mathrm{p}=0.036$ ). Genetic instability was detected in $94 \%$ of low hMLH1 and $92 \%$ of low hMSH2 staining tumors. Relapse and cancer specific death correlated with genetic instability ( $\mathrm{p}=0.01$ and 0.04 respectively). Overall $9 \%$ of tumors exhibited reduced mismatch repair expression, microsatellite instability and an unfavorable clinical outcome.

Conclusions: Mismatch repair expression and genetic instability define testis cancers with distinct molecular properties and clinical behavior. In conjunction with pathologic examination and serum tumor markers, mismatch repair expression may be an important determinant for clinical management of men with this malignancy.

Keywords: hMSH2. hMLH1. Testicular cancer. Microsatellite instability. Immunohistochemistry.

Fuente de Financiamiento: FONDECYT № 1020695 (Fondo Nacional de Desarrollo Científico y tecnológico, Chile). 
$\mathrm{L}$ os genes de reparación de errores (Mismatch repair genes) son los responsables de coordinar la corrección de nucleótidos mal incorporados durante la replicación del $\mathrm{ADN}$. La mutación e inactivación del gen prototipo, hMSH2, ha sido descrita como un factor predisponente para el desarrollo de algunos cánceres familiares como el cáncer colorectal no poliposo hereditario (HNPCC), esta mutación también se asocia al desarrollo de otros tumores como endometrio, estómago, intestino delgado, sistema hepatobiliar, riñón, uréter y ovario ${ }^{1-5}$. Se ha demostrado que el HNPCC es secundario a una mutación en la línea germinal de los genes de reparación (MMR) incluyendo los genes hMSH2 (2p16) ${ }^{6}$, hMLH1 $(3 p 21)^{7}$ y hPMS1 (2q31-33) ${ }^{8}$, hPMS2 $(7 \mathrm{p} 22)^{9}$. En este tipo de tumores se acumulan mutaciones somáticas en secuencias microsatélites a lo largo de todo el genoma atribuibles a defectos en los genes de reparación ${ }^{10}$. La mutación de algún gen del sistema de mismatch repair, se encuentra presente en un 90\% de los síndromes familiares de cáncer colorectal y en un $10 \%$ de los casos de tumores esporádicos ${ }^{10}$; asî también en otros cánceres también se ha demostrado su mutación en forma esporádica como en los tumores gástricos y pancreáticos ${ }^{11}$, cáncer de endometrio $^{12}$, cánceres de mama, ovario y sarcomas $^{13}$. Recientemente se ha demostrado mutaciones puntuales del hMSH2 en cultivos celulares de cánceres prostáticos ${ }^{14}$.

En el cáncer de testículo no se ha logrado identificar cuales son los factores moleculares que pueden determinar la aparición o progresión de este tumor. ${ }^{15}$. Si bien existen diferentes tipos histológicos con agresividad y potencial metastático diferente, su forma de diseminación es uniforme, metastizando hacia los ganglios linfáticos retroperitoneales como primera barrera de diseminación ${ }^{16,17}$. Actualmente los marcadores bioquímicos y radiológicos nos permiten determinar en forma indirecta el grado de diseminación tumoral, sin embargo no nos permiten determinar con más certeza el pronóstico ni evolución de los pacientes ${ }^{18}$. La utilización de parámetros moleculares puede ayudar a resolver esta interrogante.

El objetivo de este trabajo es lograr la caracterización inmunohistoquímica (IHQ) de los princi- pales genes de reparación (hMSH2 y hMLH1) en los diferentes subtipos de tumores testiculares y determinar la frecuencia de inestabilidad microsatélite (MSI), correlacionando ambas variables en conjunto y por separado con estadio tumoral, pronóstico y sobrevida.

\section{MATERIAL Y METODO}

Para este estudio se seleccionó entre el material anatomo-patológico del Departamento de Anatomía Patológica de la Universidad Católica de Chile, 118 casos de tumores testiculares de los distintos tipos histológicos que tuvieran un seguimiento clínico completo. La cirugía testicular fue realizada entre Enero de 1995 y Diciembre de 1999.

Del material previamente fijado en formalina, se obtuvieron cortes de 5 micrones para la realización de la inmunohistoquímica. Se utilizó la técnica estandarizada para el estudio de hMSH2 y hMLH1 13,19,20. En cada una de las series de placas, se utilizó como control un caso de cáncer de colon y un control negativo ( $\sin$ anticuerpo primario). Todos los casos fueron realizados en duplicado. Se deparafinizó con autodewaxer, la rehidratación se hizo con cambios sucesivos y progresivos de alcohol en diferentes concentraciones. Para lograr una adecuada expresión de los antígenos se utilizó buffer de citra 1X (antigen retrival) y proteinasa $\mathrm{K}$. El bloqueo se hizo con metanol/hidrogen preoxidase al 0,3\% y con goat serum. El anticuerpo primario (hMSH2 y hMLH1) se utilizó en concentración de $2 \mathrm{ng} / \mathrm{ml}$ (1:50). Como anticuerpo secundario se utilizó Pierce Goat Anti Mouse Biotinylated (1mg/ml) en dilución 1:200. Para el revelado se utilizó Vectastain Reagents o Extra avidin Preoxidase en dilución 1:50. El desarrollo se hizo con Fast DAB con niquel cloro (8\%). Para optimizar las condiciones técnicas y reproductibilidad de los resultados las reacciones se realizaron sobre una platina termorregulada para inmunohistoquímica, similar a los modelos utilizados en el National Cancer Institute $^{20}$.

Como método de comparación la segunda muestra se realizó con un sistema automatizado Nexes $^{\mathrm{R}}$ (ventana medical system, Tucson, Arizona, USA). El sistema de revelado para el método automatizado fue Nexes "DAB detection 
Kit" que contiene entre otros, steptoadivin unida a peroxidasa y diamino-benzadina. El sistema fue operado de acuerdo a las instrucciones del fabricante.

Un sistema de gradación se desarrollo para establecer el grado de tinción de las diferentes células tumorales basados en el grado de tinción de las células estromales, como fibroblastos, linfocitos y células musculares lisas. La graduación de la tinción consideró puntuaciones de 0 a 4, para el análisis posterior de los datos se consideró tinción de bajo grado (menor o igual a 2) y de alto grado (3 ó más) Para el análisis microsatélite (MSI) éste fue catalogado como ausente o presente según la comparación del ADN de las células normales y tumorales. La pérdida de heterozigocidad (LOH) se catalogó en forma separada. El estudio patológico e IHQ fue realizado y comparado por 2 patólogos independientes. Todos los tumores fueron sometidos a IHQ en forma separada al menos en 2 oportunidades.

En los tumores mixtos se clasificaron de acuerdo al tumor predominante en cada caso, dejando consignado el grado de expresión de los otros subtipos celulares. Para el estadio tumoral este fue definido de acuerdo a la clasificación del American Joint Commission on Cancer (AJCC), según los hallazgos clínicos, de marcadores tumorales y de imágenes al momento del diagnóstico. La recurrencia tumoral o recaída tumoral fue definida como la presencia de nuevas adenopatías, masas retroperitoneales o tumor medible en otro órgano en pacientes que ya habían regresado completamente posterior a quimioterapia completa o tratamiento con radioterapia, ya sea en forma precoz o alejada del tratamiento.

\section{Análisis Microsatélite}

La extracción del ADN, se realizó mediante micro disección con aguja, la que se hizo en los diferentes subtipos tumorales así como en el tejido testicular normal. El material obtenido por micro disección se incubó en 30 ul de Proteinasa $\mathrm{K}$ en concentración de $10 \mathrm{mg} / \mathrm{ml}$, por 48 a 72 horas. Para la reacción de PCR se utilizaron 4 ul de ADN en 35 ciclos con una temperatura de hibridización de 55 a $60^{\circ} \mathrm{C}$ dependiendo del mar- cador a utilizado. Como marcadores de inestabilidad microsatélite se utilizaron 10 marcadores mono y dinucleótidos conocidos, de menos de 250 pares de bases (D3s1283, D3s1293, D9s66, D9s113, TP53CA, D2S123, D3S1029, LNSCA (Research Genetics, Huntsville e In Vitro Gen), además de BAT 25 y BAT 26.

$\mathrm{El}$ producto de la PCR se diluyó en 30 ul de loading buffer y se utilizó un gel de secuenciación de poliacrilamida $8 \%, 8 \mathrm{M}$ urea. Para el estudio de amplificación de las secuencias de microsatélites se realizó en forma múltiple, con AmpliTac Gold (Perkin-Elmer) con una partida tipo "hot start”. El producto de la PCR de tipo multiplex fue luego diluido y sometido a una nueva reacción de PCR para cada secuencia microsatélite separadamente usando material reactivo alfa- ${ }^{32}$ P-dATP). Los productos de PCR radiactivos fueron sometidos a electroforesis en geles de secuenciación para ser posteriormente secados y expuestos.

Las reacciones de PCR fueron realizadas en 2 oportunidades separadas. Se utilizaron 10 marcadores de inestabilidad microsatélite, utilizando una grilla predeterminada según estudios previos, altamente representantes de MSI tanto para tumores urológicos como para colon ${ }^{26,37 .}$

\section{Análisis Estadístico}

Para el estudio estadístico se utilizó un análisis de significación estadística de Chi-cuadrado o Test exacto de Fisher, definiendo un p significativo < de 0.05. Para evaluar la asociación estadística de cada variable molecular, como potencial marcador predictivo o diagnóstico se uso el test de Chi-cuadrado o exacto de Fisher para las variables diagnósticas categóricas y el test $\mathrm{t}$ de student para variables diagnósticas de escala continúa.

\section{RESULTADOS}

Se recolectaron un total de 118 pacientes con tumores testiculares con diferentes tipos histológicos, se chequearon todas las biopsias y se revisaron todas las placas con los diagnósticos confirmatorios. Un total de 44 casos $(37,3 \%)$ correspondían a tumores tipo seminoma puro, y $62,7 \%$ fueron tumores mixtos o no seminomas (Tabla I). 
Tabla 1

Tipo histológico

\begin{tabular}{lcc}
\hline Tipo histológico & Frecuencia & Porcentaje \\
\hline Carcinoma Embrionario+ & 17 & 14,4 \\
Seminoma & & \\
Carcinoma Embrionario+ & 8 & 6,8 \\
Teratoma & & \\
Carcinoma Embrionario & 42 & 35,6 \\
Coriocarcinoma & 2 & 1,7 \\
Seminoma Puro & 44 & 37,3 \\
Teratoma & 5 & 4,3 \\
Total & 118 & 100 \\
\hline
\end{tabular}

\section{Análisis Immunohistoquímico}

Para la expresión de hMSH2 and hMLH1 usamos un anticuerpo monoclonal y policlonal respectivamente. El grado de correlación IHQ fue de 93\% para los observadores que clasificaron las placas. En todos los casos, hMLH1 and hMSH2 mostraron un patrón de expresión nuclear. En los túbulos seminíferos hMLH1 presentó un patrón de expresión en las células basales (premeiótico) y hMSH2 se expresó en todos los estadios de la espermatogénesis. Figs. $1 \mathrm{y} 2$.

El patrón de tinción fue similar en todos los tipos tumorales, tanto para hMSH2 y hMLH1, sin grandes diferencias entre los diferentes subtipos celulares, sin embargo destaca que los seminomas puros presentan un patrón inmunohisto-

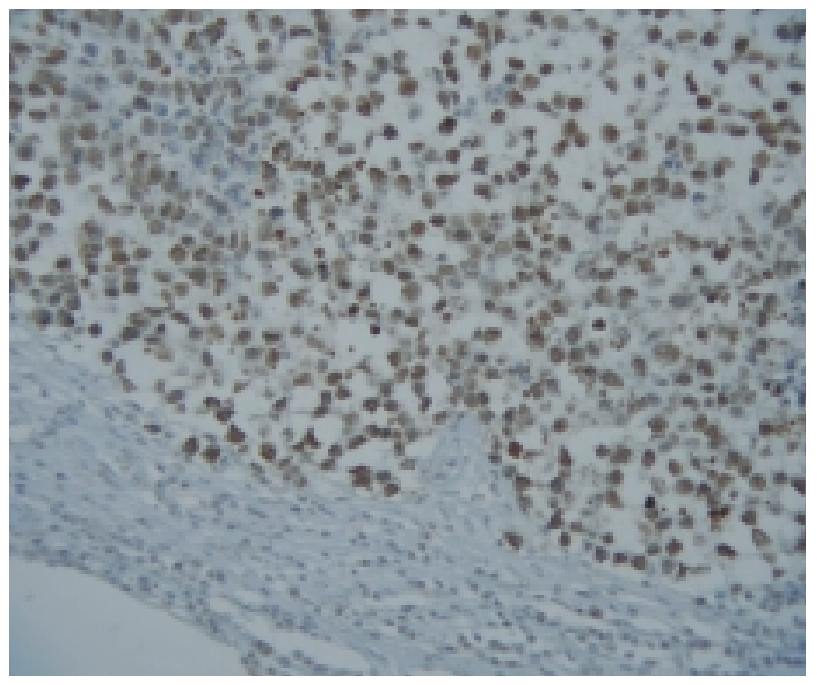

FIGURA 1. hMSH2 Seminoma. Alto grado de expresión.

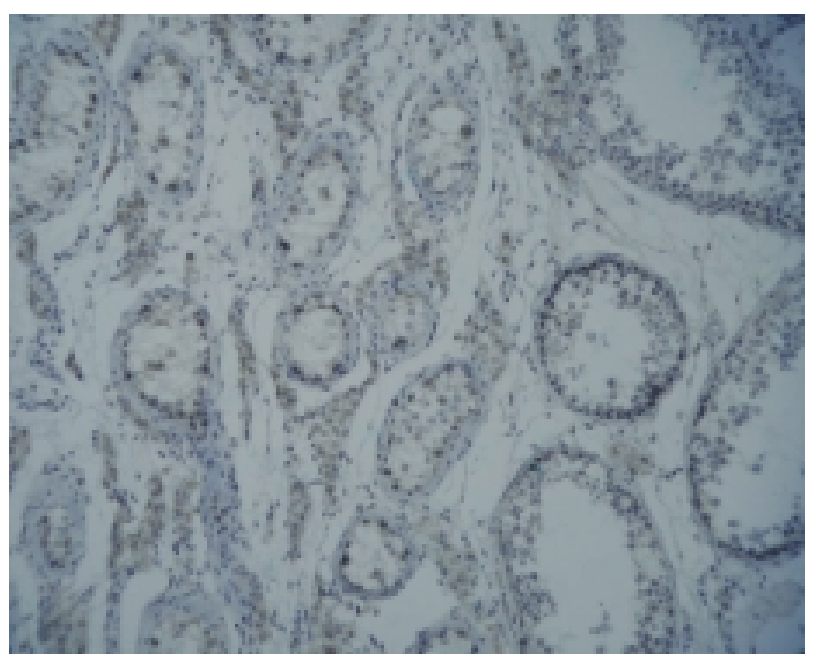

FIGURA 2. hMLH1. Túbulos Seminiferos. Células basales. Alto grado de expresión.

químico significativamente más alto para hMSH2 que los otros tipos tumorales, $(48 \%)(p=0,0046)$ Tabla II.

La correlación específica con el estadio clínico tumoral y el grado de tinción reveló que para hMLH1 de aquellos pacientes que tenían un tumor localizado (estadio I), un 58\% (50/86) presentaba una alta expresión del gen y un $41 \%$ (36/86) tenía una baja expresión. En comparación en el grupo de pacientes con tumores avanzados con metástasis al momento del diagnóstico (estadio II b o superior) en que un $34 \%(11 / 32)$ tenía una alta expresión y un $65 \%(21 / 32)$ tenía baja expresión. $\mathrm{p}=0,022$ )

Del mismo modo de los pacientes con alto grado de expresión IHQ un $82 \%(50 / 61)$ tenían enfermedad localizada y en los con bajo grado de expresión sólo un 63\% (31/57) tenía enfermedad localizada. $(\mathrm{p}<0,05)$

La IHQ de hMSH2 mostró resultados similares a los de hMLH1, siendo aun más significativo desde el punto de vista estadístico, ya que en los tumores localizados un 66\% (57/86) presentaban una alta expresión del gen y en los tumores avanzados tan sólo un 28\% (9/32) presentaba el gen estaba bien expresado ( $\mathrm{p}<0,001)$. En los tumores con alto grado de expresión IHQ un 86\% (59/66) presentaba enfermedad localizada. $(\mathrm{p}<0.05)$.

Por lo tanto el análisis estadístico reveló que en presencia de enfermedad avanzada el grado de expresión inmunohistoquímica de ambos genes es significativamente menor $(\mathrm{p}<0,05)$. 
Tabla 2

Distribución del grado de expresión IHQ de hMLH1 y hMSH2

\begin{tabular}{lcccc}
\hline Histología & \multicolumn{2}{c}{ hMLH1 } & \multicolumn{2}{c}{ hMSH2 } \\
\hline & Alto & Bajo & Alto & Bajo \\
Carcinoma Embrionario + & $11,5 \%$ & $12,3 \%$ & $10,6 \%$ & $13,5 \%$ \\
$\begin{array}{l}\text { Seminoma } \\
\text { Carcinoma Embrionario + }\end{array}$ & $4,9 \%$ & $8,8 \%$ & $7,6 \%$ & $5,8 \%$ \\
Teratoma & & & & \\
Carcinoma Embrionario & $39,3 \%$ & $31,6 \%$ & $30,3 \%$ & $42,3 \%$ \\
Coriocarcinoma & $1,6 \%$ & $1,8 \%$ & $0 \%$ & $3,8 \%$ \\
Seminoma & $36,1 \%$ & $38 \%$ & $\mathbf{4 8 , 5 \% *}$ & $\mathbf{2 3 , 1 \% *}$ \\
Teratoma & $3,3 \%$ & $5,3 \%$ & $1,5 \%$ & $7,7 \%$ \\
Total & $100 \%$ & $100 \%$ & $100 \%$ & $100 \%$ \\
\hline
\end{tabular}

* $\mathrm{p}=0,0046$

\section{Recaída tumoral e IHQ}

$\mathrm{El}$ análisis inmunohistoquímico mostró que la frecuencia de recaídas tumorales post quimioterapia es significativamente más alta en los pacientes que tenían una baja expresión de hMSH2. Así, de los pacientes con alto grado de expresión IHQ, un 16\% recurre $(11 / 66)$; en cambio de los pacientes con bajo grado de expresión del gen, un 48\% (25/52) presenta recurrencia. Del mismo modo, al observar sólo el grupo que presentó recurrencia (36 pacientes) un 69\% presentaba baja expresión del gen hMSH2. $(\mathrm{p}<0.001)$. Sin embargo no hubo diferencia estadísticamente significativa en cuanto a recurrencia según el grado de expresión IHQ de hMLH1 $(p=0,065)$.

\section{Análisis IHQ y pacientes fallecidos.}

$\mathrm{Al}$ analizar los pacientes fallecidos como consecuencia del tumor testicular (10 pacientes) (muerte cáncer específica) se puede observar que aquellos pacientes que tienen un bajo grado de expresión de hMLH1 fallecen estadísticamente más que aquellos que tienen una alta expresión del gen $(p=0,036)$. Un $80 \%$ de los pacientes fallecidos tenían una baja expresión y un $20 \%$ una alta expresión versus un $45 \%$ y $54 \%$ de los pacientes vivos.

En el caso de la expresión IHQ de hMSH2 no se observó diferencia significativa en cuanto a muerte cáncer específica. $(\mathrm{p}=0,289)$ Tabla III.
Análisis de Inestabilidad microsatélite.

Para determinar si la reducción o ausencia de la expresión de hMLH1 and hMSH2 tenía alguna correlación con la actividad del mismatch repair system, se realizó un análisis de inestabilidad microsatélite. Todas las placas fueron clasificadas según tinción de alto o bajo. Diez marcadores de inestabilidad microsatelite, que describimos previamente, se aplicaron a todas las muestras. El análisis de inestabilidad microsatélite se clasificó como inestabilidad microsatélite positiva o negativa, y separadamente se clasificó para la presencia de "loss of heterozygosity" o pérdida de heterozigocidad. (LOH) Fig. 3.
Tabla 3

Correlación muerte cáncer específica y grado de expresión IHQ de hMSH2

\begin{tabular}{lccc}
\hline IHQ hMSH2 & \multicolumn{2}{c}{ Situación } & Total \\
\cline { 2 - 3 } & Vivo & Muerto & \\
\hline Alto & 62 & 4 & 66 \\
\% con hMSH2 & $93,9 \%$ & $6,1 \%$ & $100 \%$ \\
\% con Muerto & $57,4 \%$ & $40,0 \%$ & $55,9 \%$ \\
Bajo & 46 & 6 & 52 \\
\% con hMSH2 & $88,5 \%$ & $11,5 \%$ & $100 \%$ \\
\% con Muerto & $42,6 \%$ & $60,0 \%$ & $44,1 \%$ \\
Total & 108 & 10 & 118 \\
\% con hMSH2 & $91,5 \%$ & $8,5 \%$ & $100 \%$ \\
$\%$ con Muerto & $100 \%$ & $100 \%$ & $100 \%$ \\
\hline
\end{tabular}

$(\mathrm{p}<0,289)$

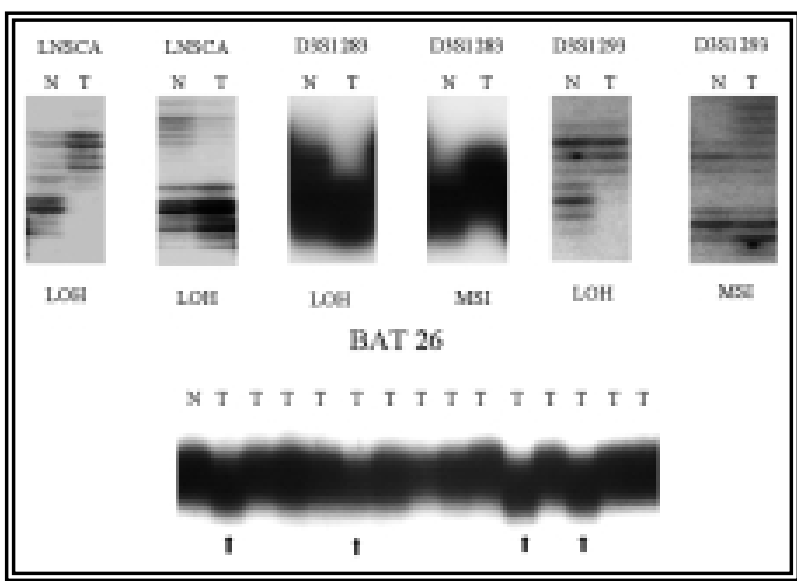

FIGURA 3. Análisis de Inestabilidad Genética. MSI: Inestabilidad Microsatélite. LOH: Pérdida de Heterozigocidad. 
En el análisis de los diferentes marcadores encontramos grados variables de MSI y de LOH según se resume en la Tabla IV. En general se observan grados variables de MSI y de LOH, no observándose diferencias significativas en el número de marcadores con MSI y LOH para cada tipo histológico específico $(\mathrm{p}=0,358 \mathrm{y}$ $\mathrm{p}=0,432$ )

$\mathrm{Al}$ analizar conjuntamente la frecuencia de MSI y la expresión IHQ de hMLH1 y hMSH2 respectivamente vemos que aquellos pacientes que tienen una baja expresión inmunohistoquímica de los genes, tienen una más alta frecuencia de inestabilidad 94\% (54/57) y 92\% $(48 / 52)$, lo que no se observa con la misma frecuencia en los pacientes con alto grado de expresión inmunohistoquímica $73 \%(45 / 61)$ y $77 \%$ (51/66). La diferencia entre ambos grupos en cuanto a inestabilidad y grado de expresión es estadísticamente significativa con valores de $\mathrm{p}=0,002$ y $\mathrm{p}=0,027$. Esta diferencia no se observa para LOH $(p=0,672$ and $p=0,036)$

La detección de inestabilidad microsatélite en los cánceres con baja expresión IHQ de hMLH1 y hMSH2 en comparación con aquellos cánceres con alta expresión de los genes es estadísticamente significativa $(\mathrm{p}<0,05)$. La presencia de MSI en más de un marcador se detectó en un $83 \%$ de los tumores estudiados.

Para determinar la importancia y correlación de la MSI en los diferentes tumores se dividió la serie en dos grupos, el primer grupo

\section{Tabla 4}

Porcentaje de expresión de MSI y de LOH según cada marcador utilizado

\begin{tabular}{lcccc}
\hline & MSI & \% & LOH & \% \\
\hline BAT 25 & 18 & 15,3 & - & - \\
BAT 26 & 12 & 10,2 & - & - \\
LNSCA & 11 & 9,3 & 60 & 50,8 \\
D3S1029 & 14 & $11, .9$ & 35 & 29,7 \\
D2S123 & 24 & 20,3 & 26 & 22 \\
TP53CA & 31 & 26,3 & 40 & 42,4 \\
D3S1283 & 23 & 19,5 & 56 & 47,5 \\
D3S1293 & 18 & 15,3 & 58 & 49,2 \\
D9S66 & 19 & 16,5 & 30 & 25,4 \\
D9S113 & 30 & 25,4 & 24 & 20 \\
\hline
\end{tabular}

con 3 marcadores con inestabilidad, y el segundo con 4 o más marcadores con MSI. Los datos muestran que aquellos enfermos que tienen más de 4 marcadores con inestabilidad presentan una mayor frecuencia de recidiva tumoral y muerte cáncer especifica. $(p=0,01$ y $\mathrm{p}=0,04)$. No se observó diferencia estadística al analizar esta variable aislada con la presencia de enfermedad avanzada al momento del diagnóstico $(\mathrm{p}=0,58)$

Al asociar el grado de expresión IHQ de hMSH2 y h MLH1 y la frecuencia de MSI, se observa que cuando existe un bajo grado de tinción y alta frecuencia de MSI $(>4)$ los pacientes presentan un estadio tumoral más avanzado y mayor recurrencia tumoral que el grupo con menos de 3 MSI y alto grado de expresión IHQ. $(p=0,018)$.

\section{DISCUSION}

La investigación inmunohistoquímica de los genes sin duda representa un desafío, ya que los criterios de los observadores no siempre son uniformes, por ello hemos utilizado observadores independientes, que comparando el grado de expresión en células tumorales y no tumorales (estromales incluidas), logran una correlación del 93\%, por lo que creemos que uniformando los criterios se pueden obtener resultados válidos.

En este trabajo investigamos la expresión IHQ de dos genes del "Mismatch repair system", ambos previamente estudiados por este grupo en la expresión de otros tumores urológicos ${ }^{14,19-21}$, encontramos que ambos genes tienen un patrón de expresión nuclear ya que actúan como es esperable tratando de reparar el ADN dañado, principalmente en la fase de síntesis del ciclo celular. En los diferentes tipos celulares encontramos que el patrón de expresión es uniforme sin observarse grandes diferencias en los distintos subtipos, sin embargo en el caso de los seminomas encontramos un alto grado de expresión para hMSH2, que fue significativamente más alto, si se le compara con los otros tipos. Es importante hacer notar que esta diferencia sólo se encontró en los tumores puros y no en los seminomas que tenían un componente mixto. El Seminoma se 
considera como el más diferenciado de los tumores testiculares y tal vez por eso el menos agresivo y con un patrón de diseminación más lento. Guizás es en este tipo tumoral más diferenciado donde hMSH2 es capaz de actuar más adecuadamente tratando de reparar el ADN dañado. Concordante con esta observación es que ambos genes se encuentra altamente expresados en los tumores localizados y su grado de expresión disminuye conforme el tumor es más avanzado (más indiferenciado). Esta observación nos permite plantear que tal vez estos genes son capaces de actuar en las primeras fases de la tumorogénesis, cuando hay daños menores en el ADN. En esta misma hipótesis de trabajo, al analizar líneas celulares de cáncer prostático encontramos que los tumores más indiferenciados de cáncer prostático (LnCap) presentaban mutación de hMSH2, y que especimenes de cáncer prostático con altos grados de Gleason presentaban también una baja expresión de hMSH2; es decir pierde su función o se inactiva cuando el daño celular en el $\mathrm{ADN}$ es mayor ${ }^{21}$. La expresión de los genes no es homogénea en todas las etapas de la tumorogénesis y es probablemente la acumulación progresiva de inactivaciones de genes de reparación y genes supresores lo que lleva a los tumores a un crecimiento más descontrolado en sus etapas finales.

Por otra parte, después de analizar los patrones de conducta de hMSH2 en tumores de testículo y próstata pareciera que éste actúa en las primeras etapas de la tumorogénesis o en estadios tumorales iniciales y tal vez por esto este gen aparece como más relevante en la recaída tumoral y no en los episodios de muerte en cáncer testicular.

La expresión IHQ de hMSH2 es homogénea en los túbulos seminíferos, tanto en las células básales como en las luminares, en todos los estadios de la espermatogénesis, sin embargo hMLH1 está expresado mayormente en las células basales, en la fase premeótica, lo que también fue observado por otros investigadores en una serie más pequeña ${ }^{22}$. Es difícil darle una interpretación a este hallazgo, pero sugiere que de alguna manera estos genes actúan en periodos diferentes de la fase de sín- tesis, por lo que tal vez su rol en la prevención de la oncogénesis puede ser diferente.

Al intentar ver la correlación que estos genes tienen como factores pronósticos en los eventos determinantes, como estadio clínico, recaída y muerte, puede ser pretencioso tratar de explicarlo sólo en base a estas variables, considerando que hay una gran cantidad de factores que pueden influir indirectamente, sobretodo en las dos últimas, ya que los enfermos recibieron quimioterapia en los de tumores avanzados, y que si bien fue el mismo esquema (esquema nacional BEP) la variabilidad de respuesta está influenciada por variables no sólo genéticas sino también ambientales. A pesar de estas limitantes llama profundamente la atención la correlación estadísticamente significativa que existe con la posibilidad de recaída o recurrencia tumoral y la muerte cáncer especifica cuando hMLH1 y hMSH2 están pobremente expresados. La baja expresión de los genes (mutación, inactivación) se tradujo en una mayor frecuencia de eventos adversos. Es destacable también que al momento del diagnóstico exista un mayor número de cánceres clínicamente avanzados cuando existe baja expresión de este gen. Similar observación ya se había registrado en tumores prostáticos en cuanto al grado de diferenciación y también en cuanto a la recidiva bioquímica posterior a prostatectomía radical.

Estos hallazgos permiten proponer un rol importante de estos genes como factor pronóstico a considerar en tumores testiculares. Tal vez estos parámetros moleculares permitan predecir las respuestas y aventurar un pronóstico, y con ello tal vez definir en el futuro terapias más agresivas en un grupo de enfermos específicos.

Otros autores han reportado MSI en cánceres prostáticos de alto grado y en cánceres avanzados sugiriendo algún rol del MMR en la progresión de las neoplasias cuando este sistema se encuentra dañado. Sin embargo, el grado de MSI en estos estudios depende del número de marcadores utilizados y del porcentaje que demuestran inestabilidad ${ }^{23-25}$. MSI ha 
sido asociada en múltiples oportunidades con agresividad, diferenciación, ploidía entre otras, así también el número de marcadores que expresan inestabilidad también parece importante al momento de tomar consideraciones, basados en ello realizamos un panel lo más amplio posible buscando al menos 10 marcadores incluidos BAT 25 y BAT 26, para determinar la relación de MSI con la IHQ y con los factores pronósticos. Como hallazgo, el número de MSI es más o menos constante en los diferentes subtipos celulares sin grandes diferencias entre ellos, y un $83 \%$ de los tumores presentaban al menos un marcadores con MSI, lo que demuestra lo preponderante de este fenómeno en los cánceres y su inespecificidad. Sin embargo cuando uno correlaciona las diferentes variables con un número más significativo de marcadores con MSI (>4) los datos son más consistentes observándose una mayor frecuencias de recaídas o recurrencia tumoral que en los pacientes que tenían poca MSI. Como parte complementaria de este estudio esperamos poder realizar el análisis de inestabilidad en un grupo seleccionados de pacientes (otra muestra) que tenían clínicamente un estadio I y que en la disección ganglionar se encontraron metástasis ganglionares; ésto podría mostrar como se manifiesta la MSI en las micro metástasis.

La correlación de las variables IHQ con MSI también muestra hallazgos importantes. Así vemos que cuando el grado de tinción es bajo, la frecuencia de MSI aumenta significativamente, y es más claro que en el subgrupo del $8 \%$ de pacientes con bajo grado de tinción y con más de 4 marcadores con MSI, el pronóstico es más malo con mayor recurrencia, estadios más avanzados y más muertes cáncer específica.

En resumen creemos que el análisis IHQ aparece como una herramienta útil para ver la expresión de hMSH2 y hMLH1 en tumores testiculares, especialmente cuando se correlaciona con el análisis de MSI, éstos pueden ser utilizados como elementos pronóstico en el futuro, entendiendo sin duda que el desarrollo de los tumores es multifuncional.

\section{REFERENCIAS}

1. Friedberg EC, Henning K, Lambert C, Saxon Pj, Schultz Ra, Sekhon Gs, Stanbridge EJ. Microcell-mediated chromosome transfer: a strategy for studying the genetics and molecular pathology of human hereditary diseases with abnormal responses to ADN damage. Basic Life Sci 1990;52:257-262.

2. Papadopoulos, N, Lindblom, A. Molecular basis of HNPCC: Mutations of MMR genes. Hum Mutat 1997;10:89-99.

3. Fishel R, Lescoe MK, Rao MRS, Copeland NG, Jenkins NA, Garber J, Kane M., Kolodner R. The human mutator gene MSH2 and its association with hereditary nonpolyposis colon cancer. Cell 1993;75:1027-1038.

4. Leach FS, Nicolaides NC, Papadopoulos N, Liu B, Jen J, Parsons R, Peltomaki P, Sistonen P, et al. Mutations of a mutS homolog in hereditary nonpolyposis colon cancer. Cell 1993;75:1215-1038.

5. Bronner CE, Baker SM, Morrison PT, Warren G, Smith LG, Lescoe MK, Kane M, Earabino C, Lipford J, et al. Mutation in the ADN mismatch repair gene homologue hMLH1 is associated with hereditary non-polyposis colon cancer. Nature. 1994;368:258-261.

6. Leach FS, Nicolaides NC. Three dinucleotide repeat polymorphisms proximal to the D2S123 locus. Hum Mol Genet 1994;3(11):2082-2083.

7. Nicolaides NC, Papadopoulos N, Liu B, Wei YF, Carter KC, Ruben SM, Rosen CA, Haseltine WA, Fleischmann RD, Fraser CM, et al. Mutations of two PMS homologues in hereditary nonpolyposis colon cancer. Nature 1994;371 (6492):75-80.

8. Papadopoulos N, Nicolaides NC, Wei YF, Ruben SM, Carter KC, Rosen CA, Haseltine WA, Fleischmann RD, Fraser CM, Adams MD, et al. Mutation of a mutL homolog in hereditary colon cancer. Science. 1994;263(5153):1559-1560.

9. Aaltonen LA, Peltomaki P, Leach FS, Sistonen P, Pylkkanen L, Mecklin JP, Jarvinen H, Powell SM, Jen J, Hamilton SR, et al. Clues to the pathogenesis of familial colorectal cancer. Science 1993;260(5109):751-755.

10. Thibodeau SN, Bren G, Schaid D. Microsatellite instability in cancer of the proximal colon. Science. 1993;260(5109): 816-819

11. Han HJ, Yanagisawa A, Kato Y, Park JG, Nakamura Y. Genetic instability in pancreatic cancer and poorly differentiated type of gastric cancer. Cancer Res. 1993; 53(21):5087-5089.

12. Charames GS, Millar AL, Pal T, Narod S, Bapat B. Do MSH6 mutations contribute to double primary cancers of the colorectum and endometrium? Hum Genet 2000;107(6):623-629.

13. Leach FS, Polyak K, Burrell M, Johnson KA, Hill D, Dunlop MG, Wylie AH, Peltomaki P, De la Chapelle A, Hamilton SR, Kinzler KW, Vogelstein B. Expression of the mismatch repair gene hMSH2 in normal and neoplastic tissues. Cancer Res.1996;56:235-240.

14. Leach FS, Velasco A, Hsieh JT, Sagalowsky AI, Mcconnell JD. The human mismatch repair gene hMSH2 is mutated in the prostate cancer cell line LNCaP. J Urol 2000;164:1830-1833.

15. Landis SH, Murray T, Bolden S, Wingo PA. Cancer statistics, 1999. CA Cancer J Clin 1999;49:8.

16. Rabbani F, Sheinfeld J, Farivar-Mohseni H, Leon A, Rentzepis MJ, Reuter VE, Herr HW, Mccaffrey JA, Motzer RJ, Bajorin DF, Bosl GJ. Low-volume nodal metastases detected at retroperitoneal lymphadenectomy for testicular cancer: pattern and prognostic factors for relapse. J Clin Oncol 2000;19(7):2020-2025. 
17. Janetschek G. Laparoscopic retroperitoneal lymph node dissection Urol Clin North Am 2001;28(1):107-114.

18. Schatte EC, Lerner SP. Recognizing abnormal marker results that do not reflect disease in patients with germ cell tumors. J Urol 2000;164(5):1670-1674.

19. Leach FS, Hsieh J.T., Molberg K, Saboorian MH, Mcconnell JD, Sagalowsky AI. Expression of the human mismatch repair gene hMSH2: a potential marker for urothelial malignancy. Cancer 2000;88:2333-2341.

20. Velasco A, Hewitt S, Saboorian H, Rosenberg H, Martinez C, Sagalowsky A, Mcconnell D, Linehan M, Leach F. Differential Expression of the Mismatch Repair Gene hMSH2 in Benign and Malignant Prostate tissue. Cancer 2002; 1,94(3):690-699.

21. Velasco A, Alberts PS, Rosenberg H, Martinez C, Leach FS. Clinicopathologic implications of hMSH2 gene expression and microsatellite instability in prostate cancer Cancer Biol Ther 2002;1(4):362-367.

22. Devouassoux-Shisheboran M, Maudit C, Bouvier R, Berger, et al. Expression of hMLH1 and hMSH2 and MSI in testicular and mediastinal germ cell tumours. Mol Hum Reprod 2001;7(12):1099-1105.
23. Watanabe M, Shiraishi T, Muneyuki T, Nagai M, Fukutom K, Murata M, Kawamura J, Yatani R. Allelic loss and microsatellite instability in prostate cancers in Japan. Oncology 1998;55:569-574

24. Dahiya R, Lee C, Mccarville J, Hu W, Kaur G, Deng G. High frequency of genetic instability of microsatellites in human prostatic adenocarcinoma. Int $\mathrm{J}$ Cancer 1997; 72:762-767.

25. Egawa S, Uchida T, Suyama K, Wang C, Ohori M, Irie S, Iwamura M, Koshiba K. Genomic instability of microsatellite repeats in prostate cancer: relationship to clinicopathological variables. Cancer Res.1995; 55: 2418- 2421.

Dr. A. Velasco

Department of Urology. Catholic University

Marcoleta 347 - Santiago, Chile

email: avelasco@med.puc.cl

(Trabajo recibido el 14 octubre 2004) 